\title{
Formulation Design of an Oral, Fast-Disintegrating Dosage Form Containing Taste-Masked Particles of Famotidine
}

\author{
Takao Mizumoto, ${ }^{*, a}$ Tetsuya Tamura, ${ }^{a}$ Hitoshi Kawai, ${ }^{a}$ Atsushi KajIyama, ${ }^{a}$ and Shigeru Itai ${ }^{b}$ \\ ${ }^{a}$ Pharmaceutical Research and Technology Labs., Astellas Pharma Inc.; 180 Ozumi, Yaizu, Shizuoka 425-0072, Japan: \\ and ${ }^{b}$ Department of Pharmaceutical Engineering and Drug Delivery Science, School of Pharmaceutical Sciences, \\ University of Shizuoka; 52-1 Yada, Suruga-ku, Shizuoka 422-8526, Japan. \\ Received February 29, 2008; accepted April 19, 2008
}

\begin{abstract}
A fast-disintegrating dosage form has been developed as a user-friendly formulation that disintegrates in the mouth immediately. Patients can take it without water like a liquid formulation. In this study famotidine tastemasking technology was applied to the new fast-disintegrating tablet in an attempt to produce a novel, tastemasked, fast-disintegrating tablet. Partial granulation was found to be an effective and practical way to address content uniformity, however, oral disintegration time tended to become longer as content uniformity improved. The disintegration time was improved considerably by controlling ambient humidity during the compression process $(>\mathbf{5 0} \% \mathbf{R H})$. Furthermore, since the new fast-disintegrating technology made it possible to use low compression force, there was no change in the structure or dissolution rate of the taste-masked particles after compression. Therefore, this system can produce a taste-masked fast-disintegrating tablet with satisfactory attributes.
\end{abstract}

Key words fast-disintegrating; famotidine; taste-masking; ambient humidity; oral disintegration time

Since the ability to swallow deteriorates with age, many elderly patients find it difficult to swallow the solid dosage forms currently available, such as tablets and capsules. In a survey conducted by Honda and Nakano, ${ }^{1)}$ half of the patients experienced difficulty taking medication. To address this problem, a fast-disintegrating, user-friendly dosage form has been developed. ${ }^{2,3)}$ This formulation disintegrates immediately in the mouth so that patients can take it without water, like a liquid formulation. This will be convenient for the patients and enhance compliance, especially for those who have difficulty swallowing solid dosage forms, or do not have ready access to water. Many companies have developed various types of fast-disintegrating dosage forms. A freeze-dried porous wafer known as Zydis, ${ }^{4,5)}$ a molding tablet known as EMP, ${ }^{6)}$ an effervescent tablet known as OraSolve, $^{7)}$ and a disintegrant addition ${ }^{8,9)}$ have all been developed. In addition, a new fast-disintegrating tablet consisting of high- and low-compressibility saccharides was reported in a previous study. ${ }^{10)}$

Most of these fast-disintegrating technologies have not been applied to bitter-tasting drugs. The objective of this study was to merge technologies to produce a taste-masked, fast-disintegrating tablet. The method for producing tastemasked particles using famotidine as a model drug by the spray-drying has been previously reported. ${ }^{11)}$ In this study, famotidine taste-masked particles were applied to the new fast-disintegrating tablet in an attempt to produce a novel, taste-masked, fast-disintegrating tablet.

\section{Experimental}

Materials D-Mannitol (Mitsubishi Shoji Foodtech, brand name: Mannit P), maltose (Hayashibara, brand name: Sanmalt), Aquacoat ECD30 (Ethylcellulose Aqueous Dispersion, FMC Corporation), triacetin (Yuki Gosei Kogyo), and calcium stearate (Nippon Oil \& Fats) were used in this study. Famotidine (Astellas Pharma Inc., JP standard) was used as the model drug.

Preparation of Taste-Masked Particles Spray dryer model CL-8 (Ohkawara kakohki) was used for the production of taste-masked particles. Famotidine powder was suspended in Aquacoat and triacetin (famotidine : Aquacoat ECD30: triacetin $=20: 6.4: 1.6)$ using a propeller mixer. This suspension was sprayed using the rotary atomizer method. The spray dry conditions were as follows: a spray rate of $20-40 \mathrm{~g} / \mathrm{min}$, a disk rotation speed of $6000-8000 \mathrm{rpm}$, and an inlet temperature of $100-120^{\circ} \mathrm{C}$.

Preparation of Fast-Disintegrating Tablets 1) Physical Mixture: Formula is shown in Table 1, formulation A. Mannitol was granulated with 5\% $(\mathrm{w} / \mathrm{w})$ maltose solution in a fluidized-bed granulator (Uni-glatt, Okawara Mfg.) and fast-disintegrating placebo granules was produced in batch size of $500 \mathrm{~g}$. The granulation conditions were as follows: a spray rate of $10 \mathrm{~g} / \mathrm{min}$, a spray pressure of $1.5 \mathrm{~kg} / \mathrm{cm}^{2}$, and a bed temperature of $28-35^{\circ} \mathrm{C}$. After mixing the placebo granules with $16 \%(\mathrm{w} / \mathrm{w})$ taste-masked particles containing $20 \mathrm{mg}$ famotidine and $0.8 \%(\mathrm{w} / \mathrm{w})$ calcium stearate, the mixture was compressed using a rotary tableting machine (Hata Seisakusho) at a compression speed of $20 \mathrm{rpm}$ to yield a tablet weight and diameter of $175 \mathrm{mg}$ and $8.5 \mathrm{~mm}$, respectively.

2) Partial Granulation: Formulas are shown in Table 1, formulations BD. A part of mannitol and $16 \%(\mathrm{w} / \mathrm{w})$ taste-masked particles in a predetermined ratio were granulated with $5 \%(\mathrm{w} / \mathrm{w})$ maltose solution in the same manner as described above. The rest of mannitol was also granulated with $5 \%(\mathrm{w} / \mathrm{w})$ maltose solution to make placebo granules. These two granule types in a predetermined ratio were mixed together with $0.8 \%(\mathrm{w} / \mathrm{w})$ calcium stearate, and then compressed in tablet weight of $175 \mathrm{mg}$ with a tablet diameter of $8.5 \mathrm{~mm}$.

3) Normal Granulation: Formulas are shown in Table 1, formulations E, F. Mannitol and $16 \%(\mathrm{w} / \mathrm{w})$ taste-masked particles were granulated with $4-5 \%$ $(\mathrm{w} / \mathrm{w})$ maltose solution in a fluidized-bed granulator in batch size of $500 \mathrm{~g}$. After mixing the granules with $0.8 \%(\mathrm{w} / \mathrm{w})$ calcium stearate, and then compressed in tablet weight of $175 \mathrm{mg}$ with a tablet diameter of $8.5 \mathrm{~mm}$.

As conditioning process, the tablets were kept in a thermostatic chamber set at $25^{\circ} \mathrm{C}$ and $70 \% \mathrm{RH}$ for $24 \mathrm{~h}$ (Tabaiespec Co., Ltd., PR-35C), followed by another period of $3 \mathrm{~h}$ at $30{ }^{\circ} \mathrm{C}$ and $40 \% \mathrm{RH}$ in the same equipment.

Control of Ambient Humidity during the Compression Process The tableting equipment was covered with a clear plastic sheet, and its interior humidity was adjusted via controlling steam and dried air as a balance. The compression study began after the target humidity had been maintained for at least $20 \mathrm{~min}$.

Recovering the Taste-Masked Particles from the Tablet The tablets were lightly crushed, and $5 \mathrm{ml}$ of purified water was added. After shaking for $30 \mathrm{~s}$, the suspension was filtered with a $0.45 \mu \mathrm{m}$ filter. The water-insoluble substances were recovered from the filter paper and dried at $40^{\circ} \mathrm{C}$ overnight.

Tablet Characteristics Measurement of oral disintegration time was performed using 3-4 volunteers. Each volunteer washed his/her mouth well with tap water, and then allowed a tablet to disintegrate in his/her mouth. The time required for disintegration without chewing was measured, after which the tablet was immediately spat out.

Hardness $(n=5)$ was measured using a hardness tester (Schleuniger, model 6D), and the thickness $(n=3)$ of the tablet was measured using a dial thickness gauge (Teclock). Tablet weight was indicated as the mean weight 
Table 1. Formulas of Tablets with Various Granulation Methods

\begin{tabular}{|c|c|c|c|c|c|c|}
\hline & $\begin{array}{c}\text { Formulation A } \\
\text { Physical } \\
\text { mixture }\end{array}$ & $\begin{array}{l}\text { Formulation B } \\
\text { Partial } \\
\text { granulation } \\
(1: 1)^{a)}\end{array}$ & $\begin{array}{c}\text { Formulation C } \\
\text { Partial } \\
\text { granulation } \\
(1: 2)^{a)}\end{array}$ & $\begin{array}{l}\text { Formulation D } \\
\text { Partial } \\
\text { granulation } \\
(1: 4)^{a)}\end{array}$ & $\begin{array}{c}\text { Formulation E } \\
\text { Normal } \\
\text { granulation }\end{array}$ & $\begin{array}{c}\text { Formulation F } \\
\text { Normal } \\
\text { granulation }\end{array}$ \\
\hline Taste-masked particles & 28 & 28 & 28 & 28 & 28 & 28 \\
\hline Mannitol & - & 54.4 & 81.9 & 103.9 & 136.85 & 138.6 \\
\hline Maltose & - & 4.38 & 5.8 & 7 & 8.75 & 7 \\
\hline \multicolumn{7}{|l|}{ Placebo granules } \\
\hline Mannitol & 136.85 & 82.45 & 55 & 33 & - & - \\
\hline Maltose & 8.75 & 4.38 & 2.9 & 1.7 & - & - \\
\hline Calcium stearate & 1.4 & 1.4 & 1.4 & 1.4 & 1.4 & 1.4 \\
\hline Total (mg) & 175 & 175 & 175 & 175 & 175 & 175 \\
\hline
\end{tabular}

a) Ratio of placebo granules to partial granules.

of 10 tablets, and friability was calculated by weight loss after 100 revolutions at $25 \mathrm{rpm}$ (Pharmatest, PTFR-A). Moisture content of tablet was measured by Karl-Fischer method using 5 tablets.

Adsorption Isotherm An automatic vapor adsorption apparatus (VTI, SGA-100) was used to measure the adsorption profiles for about $10 \mathrm{mg}$ of granules containing amorphous maltose. The sample was prepared by grinding granules or tablet using mortar. The adsorption profile was measured at predetermined relative humidity after drying the sample for at least $2 \mathrm{~h}$ at $60^{\circ} \mathrm{C}$

Dissolution Testing Dissolution testing of tablets containing tastemasked particles of famotidine $(20 \mathrm{mg})$ was performed using the paddle method at $50 \mathrm{rpm}$ in water. For taste-masked particles, $\mathrm{pH} 6.8$ buffer containing $0.1 \%$ Tween 80 was used because of a low wettability of particle. Famotidine was detected using the UV method $(265 \mathrm{~nm})$.

Evaluation of Particle Surface Using Scanning Electron Micrographs The surface morphology of the taste-masked particle was observed using scanning electron microscopy (JEOL, JSM-5510LV).

Determination of Particle Size Distribution The size distribution of taste-masked particles was measured using a robot sifter (RPS-85, Seishin Enterprise)

\section{Results and Discussion}

Determination of the Amount of Maltose as a Granulation Binder To achieve objectives, the criteria for tablet characteristics were summarized in Table 2. The hardness was more than $30 \mathrm{~N}$, and the friability was less than $1 \%$ after 100 revolutions to assure adequate durability during handling. The oral disintegration time was $20-30 \mathrm{~s}$ or less for a fast-disintegrating tablet. The dissolution rate was less than $30 \%$ at $1 \mathrm{~min}$ (to suppress the bitter taste of famotidine), but more than $85 \%$ at $15 \mathrm{~min}$ (to obtain a good bioavailability). ${ }^{11 \text { ) }}$

To determine the amount of maltose that should be used as binder in the formulation, tablets containing 2,3 , and $5 \%$ (w/w) maltose were all manufactured to compare their characteristics. During compression, the relative humidity was controlled at two levels, about $40 \% \mathrm{RH}$ and about $50 \% \mathrm{RH}$, and the compression force was adjusted so that about $15 \mathrm{~N}$ of initial hardness could be obtained. Table 3 shows the properties of tablets granulated with different amounts of maltose and compressed at different ambient humidity levels.

Oral disintegration time was shorter for the tablets manufactured at $50 \% \mathrm{RH}$ than those at $40 \% \mathrm{RH}$ and showed statistically significant difference at 3 and $5 \%(\mathrm{w} / \mathrm{w})$ maltose $(p<0.05)$. Sebhatu et al. $\left.{ }^{12}\right)$ reported an increased moisture content gave an increased tablet tensile strength. Consequently, it was presumed that the humidity helped increase of compressibility, thereby allowing the target initial hardness, $15 \mathrm{~N}$, to be obtained at a lower compression force. As a result, tablet thickness and porosity increased, which led to a
Table 2. Criteria for Tablet Characteristics

\begin{tabular}{ll}
\hline \hline \multicolumn{1}{c}{ Tablet characteristics } & Criteria \\
\hline Hardness & $>30 \mathrm{~N}$ \\
Friability at 100 revolutions & $<1 \%$ \\
Oral disintegration time & $<20-30 \mathrm{~s}$ \\
Dissolution rate at $1 \mathrm{~min}$ & $<30 \%$ \\
Dissolution rate at $15 \mathrm{~min}$ & $>85 \%$ \\
\hline
\end{tabular}

shorter oral disintegration time. Thus, controlling ambient humidity is an effective and practical way to improve oral disintegration time. Furthermore tablet hardness increased about $30 \mathrm{~N}$ via a conditioning process which changed amorphous maltose to crystal state and achieved the target hardness.

When $2 \%(\mathrm{w} / \mathrm{w})$ maltose was used as a binder, the disintegration time was prolonged, even at $50 \% \mathrm{RH}$, because of high compression force and decreased thickness that led to the low porosity of tablet. In contrast, there was no difference in the tablet properties when $3 \%(\mathrm{w} / \mathrm{w})$ and $5 \%(\mathrm{w} / \mathrm{w})$ maltose were used, and both $3 \%(\mathrm{w} / \mathrm{w})$ and $5 \%(\mathrm{w} / \mathrm{w})$ maltose tablets manufactured at 50\% RH met the target disintegration time within $20 \mathrm{~s}$. Since 3\% (w/w) maltose was not considered to be enough binder amounts for forming the target granules, $4-5 \%(\mathrm{w} / \mathrm{w})$ was selected as the amount of maltose. However, the friability needed to be improved in further investigation, since that of $5 \%(\mathrm{w} / \mathrm{w})$ maltose tablets did not meet the criteria (less than $1 \%$, based on USP).

Improvement of Content Uniformity Since physical mixture is a simple and low cost process, the physical mixing of taste-masked particles and fast-disintegrating placebo granules which was granulated mannitol with $5 \%(\mathrm{w} / \mathrm{w})$ maltose was attempted. The physical mixture of taste-masked particles and fast-disintegrating placebo granules was compressed after $30 \mathrm{~min}$ of mixing. The tablet taken at each sampling time and whole tablets were then assayed and tested for content uniformity (Tables 1 and 4, formulation A). Although the $\mathrm{CV} \%$ for the content uniformity at each sampling time were less than $2 \%$, that of the whole tablets was more than $3 \%$, which was unacceptable. The reason for high CV\%, found in the whole tablets, was that the flowability between taste-masked particles and fast-disintegrating placebo granules was quite difference. Therefore, the physical mixture method was deemed inappropriate.

In an attempt to improve content uniformity, the partial 
Table 3. Properties of Tablets Granulated with Different Amounts of Maltose and Compressed at Different Ambient Humidity Levels

\begin{tabular}{|c|c|c|c|c|c|c|}
\hline \multirow[b]{2}{*}{ Ambient humidity } & \multicolumn{2}{|c|}{$2 \%(\mathrm{w} / \mathrm{w})$ maltose } & \multicolumn{2}{|c|}{$3 \%(\mathrm{w} / \mathrm{w})$ maltose } & \multicolumn{2}{|c|}{$5 \%(\mathrm{w} / \mathrm{w})$ maltose } \\
\hline & $\begin{array}{c}24{ }^{\circ} \mathrm{C} \\
43 \% \mathrm{RH}\end{array}$ & $\begin{array}{c}25^{\circ} \mathrm{C} \\
52 \% \mathrm{RH}\end{array}$ & $\begin{array}{c}24^{\circ} \mathrm{C} \\
43 \% \mathrm{RH}\end{array}$ & $\begin{array}{c}26^{\circ} \mathrm{C} \\
51 \% \mathrm{RH}\end{array}$ & $\begin{array}{c}24^{\circ} \mathrm{C} \\
42 \% \mathrm{RH}\end{array}$ & $\begin{array}{c}25^{\circ} \mathrm{C} \\
52 \% \mathrm{RH}\end{array}$ \\
\hline Compression force $(\mathrm{kN})$ & 1.7 & 1.5 & 1.7 & 1.0 & 1.5 & 0.8 \\
\hline Tablet weight (mg) & 176.1 & 175.2 & 177.5 & 174.8 & 176.9 & 174.5 \\
\hline Thickness (mm) & $3.67 \pm 0.01$ & $3.67 \pm 0.01$ & $3.74 \pm 0.01$ & $3.81 \pm 0.01$ & $3.8 \pm 0.01$ & $3.96 \pm 0.01$ \\
\hline Initial hardness $(\mathrm{N})$ & $14 \pm 0.9$ & $13 \pm 0.5$ & $16 \pm 0.5$ & $14 \pm 1.9$ & $15 \pm 0.5$ & $14 \pm 0.7$ \\
\hline Treated hardness $(\mathrm{N})$ & $27 \pm 1.9$ & $27 \pm 0.7$ & $36 \pm 1.3$ & $27 \pm 0.8$ & $41 \pm 1.5$ & $32 \pm 0.7$ \\
\hline Friability (100 revolutions, \%) & 1.33 & 1.30 & 0.91 & 1.65 & 0.80 & 1.20 \\
\hline Oral disintegration time (s) & $25 \pm 0.7$ & $24 \pm 2.5$ & $20 \pm 0.7$ & $15 \pm 2.1 *$ & $22 \pm 1.4$ & $14 \pm 1.4^{*}$ \\
\hline
\end{tabular}

Mean \pm S.D. $*$-test, $p<0.05$.

Table 4. Effect of Granulation Method on the Content Uniformity of the Tablet

\begin{tabular}{|c|c|c|c|c|c|c|c|c|c|c|}
\hline \multirow[t]{2}{*}{ Tableting time } & \multicolumn{2}{|c|}{$\begin{array}{c}\text { Formulation A } \\
\text { Physical } \\
\text { mixture }\end{array}$} & \multicolumn{2}{|c|}{$\begin{array}{c}\text { Formulation B } \\
\text { Partial } \\
\text { granulation }(1: 1)^{b)}\end{array}$} & \multicolumn{2}{|c|}{$\begin{array}{c}\text { Formulation C } \\
\text { Partial } \\
\text { granulation }(1: 2)^{b)}\end{array}$} & \multicolumn{2}{|c|}{$\begin{array}{c}\text { Formulation D } \\
\text { Partial } \\
\text { granulation }(1: 4)^{b)}\end{array}$} & \multicolumn{2}{|c|}{$\begin{array}{l}\text { Formulation E } \\
\text { Normal } \\
\text { granulation }\end{array}$} \\
\hline & Assay (\%) & $\left.\mathrm{CV}^{0}{ }^{a}\right)$ & Assay (\%) & $\left.\mathrm{CV} \%{ }^{a}\right)$ & Assay (\%) & $\mathrm{CV} \%{ }^{a)}$ & Assay (\%) & $\mathrm{CV} \%{ }^{a)}$ & Assay (\%) & $\mathrm{CV}^{0}{ }^{a)}$ \\
\hline Start & 92 & 1.17 & 97 & 1.59 & 106 & 1.71 & 101 & 0.89 & 101 & 1.15 \\
\hline $20 \mathrm{~min}$ & - & - & - & - & 109 & 1.76 & - & - & - & - \\
\hline $40 \mathrm{~min}$ & 98 & 1.53 & 102 & 1.02 & 111 & 1.31 & 100 & 1.68 & 103 & 0.91 \\
\hline $60 \mathrm{~min}$ & - & - & - & - & 110 & 1.33 & - & - & - & - \\
\hline $80 \mathrm{~min}$ & 100 & 1.08 & 102 & 0.94 & - & - & 101 & 1.35 & 105 & 1.81 \\
\hline Whole tablet & 96 & 3.67 & 100 & 2.47 & 109 & 2.32 & 101 & 1.36 & 103 & 1.84 \\
\hline Oral disintegration time $(\mathrm{s})^{c)}$ & \multicolumn{2}{|c|}{$13 \pm 2.5$} & \multicolumn{2}{|c|}{$16 \pm 1.0$} & \multicolumn{2}{|c|}{$17 \pm 2.5$} & \multicolumn{2}{|c|}{$24 \pm 4.5$} & \multicolumn{2}{|c|}{$26 \pm 3.5$} \\
\hline
\end{tabular}

a) Coefficient of variation. b) Ratio of placebo granules to partial granules. c) Mean \pm S.D.

granulation method was tried (Tables 1 and 4 , formulations B-D). A part of mannitol and taste-masked particles were granulated with $5 \%(\mathrm{w} / \mathrm{w})$ maltose, and this granule was mixed with placebo granule at predetermined ratios (placebo granule : partial granule $=1: 1$ to $1: 4$ ). As with the physical mixture, the $\mathrm{CV} \%$ at each sampling time were within the target value in all lots. Furthermore, the $\mathrm{CV} \%$ for whole tablets improved with the increase in the ratio of partial granulation, with formulation D $(1: 4)$ showing a good $\mathrm{CV} \%$ of less than $2 \%$. The reason was that the high flowability of taste-masked particles by partial granulation with mannitol was closely related to that of fast-disintegrating placebo granules. However, the oral disintegration time was longer as the ratio of partial granulation increased (more than $20 \mathrm{~s}$ for formulation D). Furthermore, the normal granulation (Tables 1 and 4, formulation E), which was granulated the mixture of tastemasked particles and all of the mannitol with $5 \%(\mathrm{w} / \mathrm{w})$ maltose, showed a good CV\% for content uniformity, but disintegration time was prolonged. In conclusion, the granulation of mannitol and taste-masked particles improved content uniformity, but prolonged oral disintegration time.

Improvement of Oral Disintegration Time It would be possible to improve oral disintegration time by controlling moisture content as shown in Table 3. Since moisture content in granules was easy to control by drying condition in granulation process, the control of granule moisture content was investigated in an attempt to improve the oral disintegration time. However, the granules containing amorphous maltose absorbed moisture readily as referred to hereinafter (Fig. 1), and it was predicted granule moisture content was easily changed by ambient humidity over the course of compres-

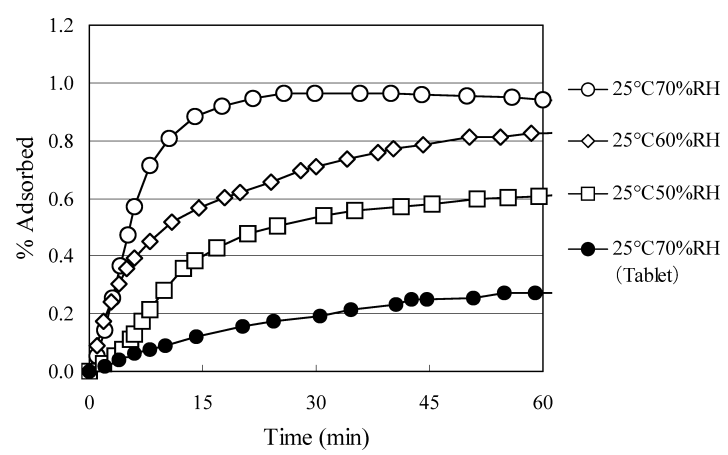

Fig. 1. Adsorption Profiles of Granules and Tablet under Different Relative Humidity

sion. Therefore, considering commercial production, the control of granule moisture content was not a valid approach for improving oral disintegration time.

The effect of ambient humidity during the compression process on tablet characteristics was examined in detail in an attempt to enhance oral disintegration time. The mixture of taste-masked particles and mannitol was granulated with $4 \%$ $(\mathrm{w} / \mathrm{w})$ maltose (normal granulation) and mixed with $0.8 \%$ $(\mathrm{w} / \mathrm{w})$ calcium stearate (Table 1, formulation F). When these granules were stored at 50,60, and $70 \% \mathrm{RH}$, the granule adsorbed moisture rapidly as shown in Fig. 1. The reason for this rapid adsorption was that the maltose used as the binder was present in an amorphous state that absorbed moisture readily as described previously. ${ }^{10)}$ As a consequence, compression was started after the granules had been allowed to sit in the tablet equipment under controlled ambient humidity 
Table 5. Effect of Ambient Humidity during Compression on Tablet Characteristics

\begin{tabular}{|c|c|c|c|c|c|}
\hline Ambient humidity during compression & $23{ }^{\circ} \mathrm{C} 30 \% \mathrm{RH}$ & $23{ }^{\circ} \mathrm{C} 40 \% \mathrm{RH}$ & $24^{\circ} \mathrm{C} 50 \% \mathrm{RH}$ & $23^{\circ} \mathrm{C} 57 \% \mathrm{RH}$ & $24{ }^{\circ} \mathrm{C} 65 \% \mathrm{RH}$ \\
\hline Compression force $(\mathrm{kN})$ & 1.8 & 1.8 & 1.6 & 1.4 & 0.99 \\
\hline Tablet weight (mg) & 175.4 & 175.2 & 175.1 & 175.4 & 175.2 \\
\hline Thickness (mm) & $3.76 \pm 0.01$ & $3.74 \pm 0.01$ & $3.74 \pm 0.01$ & $3.82 \pm 0.01$ & $3.85 \pm 0.01$ \\
\hline Moisture content of initial tablet (\%) & - & 0.54 & 0.59 & 0.62 & 0.82 \\
\hline Initial hardness $(\mathrm{N})$ & $15 \pm 1.3$ & $16 \pm 0.9$ & $15 \pm 0.9$ & $16 \pm 1.1$ & $15 \pm 1.6$ \\
\hline Treated hardness $(\mathrm{N})$ & $41 \pm 1.3$ & $38 \pm 4.4$ & $37 \pm 2.3$ & $35 \pm 2.6$ & $34 \pm 1.9$ \\
\hline Friability (100 revolutions, \%) & 0.22 & 0.30 & 0.32 & 0.29 & 0.17 \\
\hline Oral disintegration time (s) & $25 \pm 3.0$ & $23 \pm 1.5$ & $19 \pm 1.5^{*}$ & $17 \pm 2.6^{*}$ & $14 \pm 2.4^{*}$ \\
\hline
\end{tabular}

Each values represent the mean \pm S.D. $* t$-test, $p<0.05$ compared with value of $23{ }^{\circ} \mathrm{C} 30 \% \mathrm{RH}$.

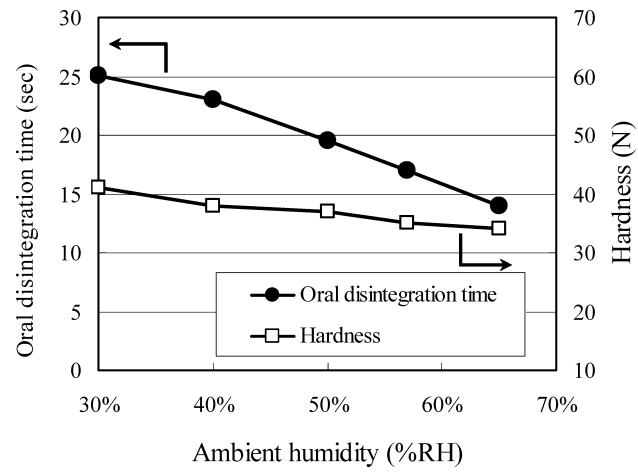

Fig. 2. Relationship between Ambient Humidity during Compression and Oral Disintegration Time and Hardness

$(30-65 \% \mathrm{RH})$ for more than $20 \mathrm{~min}$ to equilibrate to the target humidity.

When the initial hardness was set at $15 \mathrm{~N}$, the compression force decreased with the increase in ambient humidity and with the increase of moisture content of tablets as shown in Table 5. Figure 2 shows the relationship between ambient humidity during the compression process and oral disintegration time or hardness. The hardness kept more than $30 \mathrm{~N}$ which was a sufficient strength level for handling, even though ambient humidity increased. In contrast, oral disintegration time was shorter as ambient humidity increased, and reached the target value (less than $20 \mathrm{~s}$ ) at RH levels of more than $50 \%$. Oral disintegration time at more than $50 \% \mathrm{RH}$ showed statistically significant difference from that of $30 \%$ $\mathrm{RH}(p<0.05)$. It was presumed that humidity would play a peripheral role in the enhancement of compressibility. Consequently, it was confirmed that controlling ambient humidity during the compression process at more than $50 \% \mathrm{RH}$ was a promising way to achieve quick disintegration.

The friability was also improved to less than $1 \%$ as shown in Table 5 , since the adequate strength was achieved by appropriate selection of granulation and compression conditions. Furthermore, since amorphous maltose was intentionally changed into the crystalline state via a conditioning process, the tablet hardly adsorbed any moisture, even at $25^{\circ} \mathrm{C} 70 \% \mathrm{RH}$ (Fig. 1). Under these conditions, tablet characteristics like hardness was expected to be stable during storage. Figure 3 shows the stability of tablet hardness under $25^{\circ} \mathrm{C} 75 \% \mathrm{RH}$ storage conditions in opened bottle and PVC blister packaging forms and both hardness were stable for 6 months as expected.

Influence of Compression Force on the Characteristics of Taste-Masked Particles In general, when a tablet con-

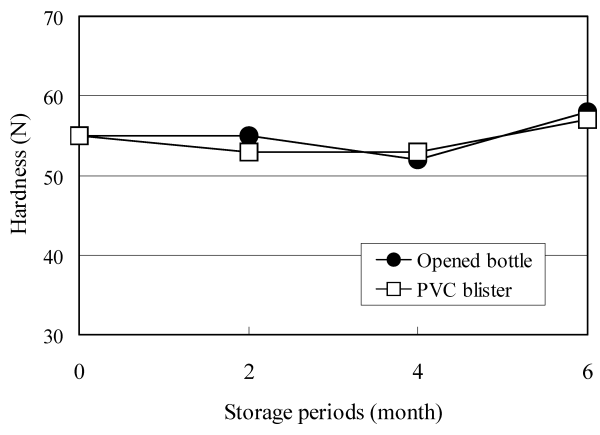

Fig. 3. Stability of Tablet Hardness under $25^{\circ} \mathrm{C} 75 \%$ RH Storage Conditions

tained dissolution-controlled particles, the dissolution-control attribute was generally damaged by compression force and its dissolution rate was accelerated. However, the new fast-disintegrating technology ${ }^{10}$ applied in this study would be produced with low compression pressure and enable to avoid damage to the dissolution-control attribute. The new fast-disintegrating formulation included high- and low-compressibility saccharides. The high-compressibility saccharide used as a binder solution was present in an amorphous state after the granulation process. The change from the amorphous to crystalline state was induced intentionally via a post-compression conditioning process that strengthened adhesion between particles in the tablet, thereby enhancing hardness. Therefore, the application of this new fast-disintegrating technology was not expected to damage the dissolution-control attribute because the tablets were compressed with low force, while still maintaining sufficient hardness.

Figure 4 shows scanning electron micrographs of (a) intact taste-masked particles and (b) particles recovered from tablets (Table 1, formulation F). The surface of the intact taste-masked particle was coated smoothly with no observable famotidine crystals. In contrast, the surface of the recovered particle was a little bit rough due to being recovered via water washing, but its spherical structure remained intact. Therefore, it could be concluded that the structure of tastemasked particles was not damaged by compression pressure, and the taste-masked attribute was maintained. Furthermore, the distributions of taste-masked particles recovered from tablets (Table 1, formulation F) compressed under different pressures were evaluated and compared to that of the intact taste-masked particles (Table 6). For all tablets, the mean size of the particles was almost the same as that of intact particles. The particle distributions were also identical. These re- 

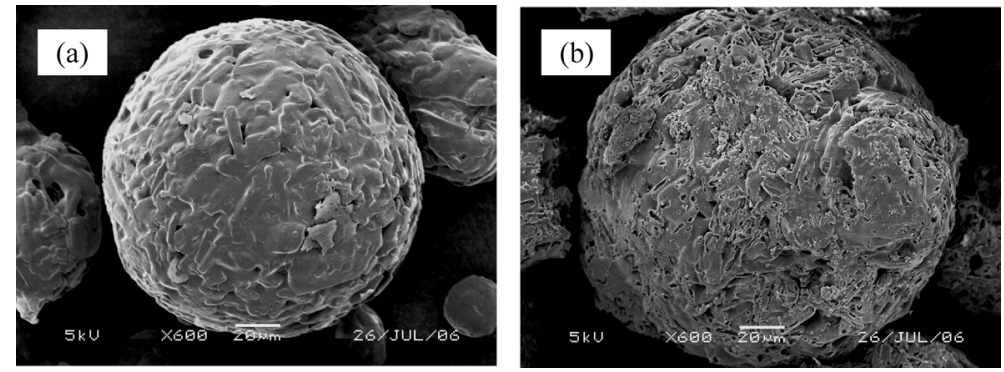

Fig. 4. Scanning Electron Micrographs of (a) Intact Taste-Masked Particles and (b) Particles Recovered from Tablets

Table 6. Particle Distribution of Intact Taste-Masked Particles and Particles Recovered from Tablets

\begin{tabular}{lcccc}
\hline \hline & $\begin{array}{c}\text { Intact taste-masked } \\
\text { particles }\end{array}$ & $\begin{array}{c}\text { Particles recovered from } \\
\text { tablets compressed } \\
\text { at } 2 \mathrm{kN}\end{array}$ & $\begin{array}{c}\text { Particles recovered from } \\
\text { tablets compressed } \\
\text { at 4kN }\end{array}$ & $\begin{array}{c}\text { Particles recovered from } \\
\text { tablets compressed } \\
\text { at } 6 \mathrm{kN}\end{array}$ \\
\hline Mean particle size $(\mathrm{mm})$ & 79.3 & 72.8 & 82.3 & \\
Particle distribution $(\%)$ & & & & 78.6 \\
$150 \mu \mathrm{m}-$ & 6.0 & 4.2 & 9.0 & 6.4 \\
$106-150 \mathrm{~mm}$ & 23.0 & 22.3 & 23.9 & 23.9 \\
$45-106 \mu \mathrm{m}$ & 57.3 & 57.5 & 57.9 & 57.9 \\
$45 \mu \mathrm{m}$ or less & 13.1 & 16.0 & 11.8 & 11.8 \\
\hline
\end{tabular}

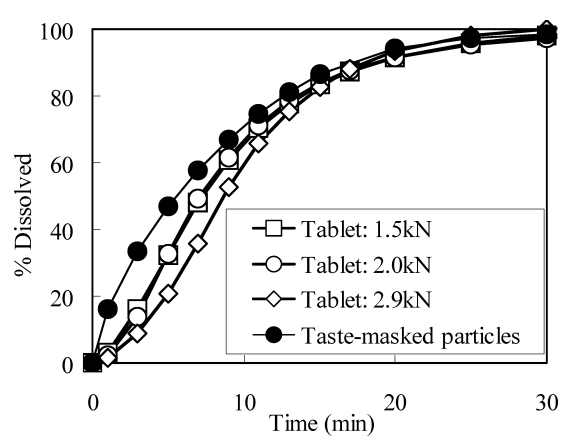

Fig. 5. Dissolution Profiles for Famotidine from Tablets Compressed at Various Pressures and Taste-Masked Particles by Paddle Method at $50 \mathrm{rpm}$ in Water for Tablet and in $\mathrm{pH} 6.8$ Containing $0.1 \%$ Tween 80 for TasteMasked Particles

sults suggested that taste-masked particles were not crushed during compression. Figure 5 shows the dissolution rates of tablets (Table 1, formulation F) compressed at various pressures and taste-masked particles as reference. Dissolution rates of all tablets showed the almost the same as tastemasked particles, although dissolution medium for tastemasked particles was $\mathrm{pH} 6.8$ buffer containing $0.1 \%$ Tween 80 because of a low wettability of particle. Namely dissolution rates of tablets were not affected by compression pressure. It was confirmed that compression did not affect the taste-masking attribute and those tablets conformed to the target dissolution rates, $\mathrm{D} 1 \mathrm{~min}<30 \%$ and $\mathrm{D} 15 \mathrm{~min}>85 \%$, and showed no bitter taste of famotidine.

In conclusion, partial granulation was an effective way to solve the content uniformity problem, even for tablets con- taining taste-masked particles. Unfortunately, oral disintegration time tended to be longer as content uniformity improved. However, when ambient humidity was maintained at $50 \% \mathrm{RH}$, or more during compression, a quick disintegration time was achieved. In addition, since the new fast-disintegrating technology made it possible to compress at a low compression force, no changes in the structure or dissolution rate of the taste-masked particles occurred after compression. Therefore, the system described in this report successfully produced a taste-masked, fast-disintegrating tablet with satisfactory attributes.

\section{References}

1) Honda Y., Nakano M., Jpn. J. Hosp. Pharm., 24, 533-540 (1998).

2) Chang R. K., Guo X., Burnside B. A., Couch R. A., Pharm. Technol., 6, $52-58(2000)$.

3) Sandri G., Bonferoni M. C., Ferrari F., Rossi S., Caramella C., Am. J. Drug Deliv., 4, 249-262 (2006).

4) Seager H., J. Pharm. Pharmacol., 50, 375-382 (1998).

5) Katou S., Kearney P., Yarwood R. J., Pharm. Tech. Jpn., 9, 713-719 (1993).

6) Tushima Y., J. Jpn. Soc. Pharm. Mach. Eng., 10, 5-17 (2001).

7) Wehling F., Schuehle S., Madamala N., WO91/04757 (1991).

8) Ishikawa T., Mukai B., Shiraishi S., Utoguchi N., Fujii M., Matsumoto M., Watanabe Y., Chem. Pharm. Bull., 49, 134-139 (2001).

9) Shimizu T., Sugaya M., Nakano Y., Izutsu D., Mizukami Y., Okochi K., Tabata T., Hamaguchi N., Igari Y., Chem. Pharm. Bull., 51, 11211127 (2003).

10) Mizumoto T., Masuda Y., Yamamoto T., Yonemochi E., Terada K., Int. J. Pharm., 306, 83-90 (2005).

11) Mizumoto T., Tamura T., Kawai H., Kajiyama A., Itai S., Chem. Pharm. Bull., 56, 530-535 (2008).

12) Sebhatu T., Ahlneck C., Alderborn G., Int. J. Pharm., 146, 101-114 (1997). 